\title{
KEY FACTS ON FOUNDATIONS' PUBLIC POLICY-RELATED ACTIVITIES
}

In recent years, more U.S. foundations have become engaged in efforts to inform the policymaking process. From education, to health care, to the arts, grantmakers are supporting efforts to conduct research, educate the public, and provide resources to policymakers to achieve deeper and more far-reaching outcomes.

To benchmark the level of foundation engagement in these efforts and the types of activities they support, the Foundation Center included a series of public policy-related questions in its early 2010 Foundation Giving Forecast Survey. More than 1,300 independent, corporate, and community foundations responded, with 315 indicating that they currently engage in public policy-related activities. Following are key findings from the survey.

\section{How widespread is foundation support for public policy-related activities?}

- About one-quarter of surveyed foundations currently either fund or engage in direct charitable activities that could be considered public policy-related.

- The level of engagement in public policy-related activities does not vary greatly by foundation type. Independent and community foundations are only slightly more likely to provide public policy-related support than corporate foundations.

- By foundation size, larger foundations are far more likely to fund in this area. Almost half (46 percent) of surveyed foundations with total giving of $\$ 10$ million or more reported public policy-related support, compared to 14 percent for those foundations that had total giving under \$1 million.
Foundation Engagement in Public Policy-related Activities, 2010

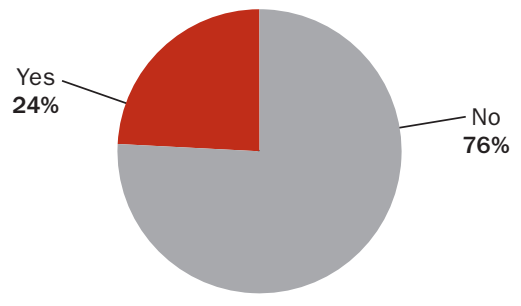

Percent of All Respondents

Source: The Foundation Center, Key Facts on Foundations' Public Policy-related Activites, 2010. Based on the responses of 1,309 foundations.

Foundation Engagement in Public Policy-related Activities by Foundation Type, 2010

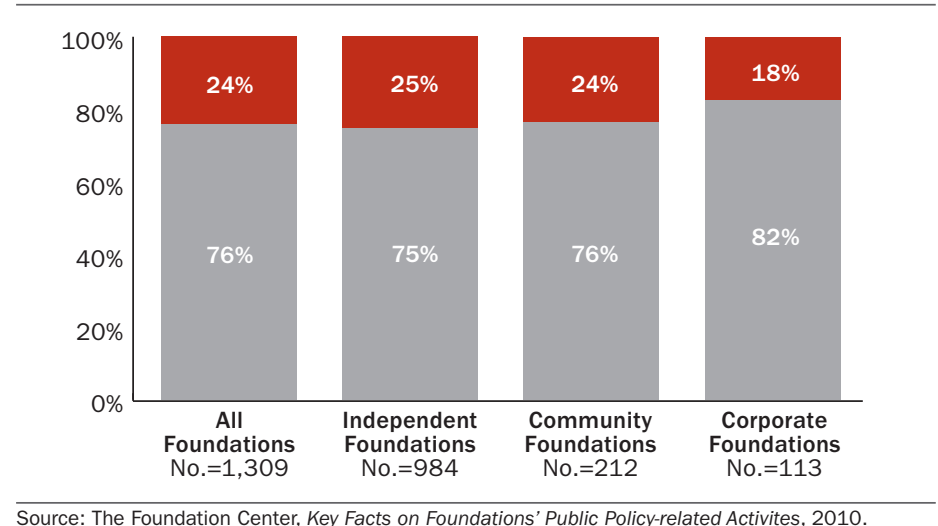

Foundation Engagement in Public Policy-related Activities by Foundation Size, 2010

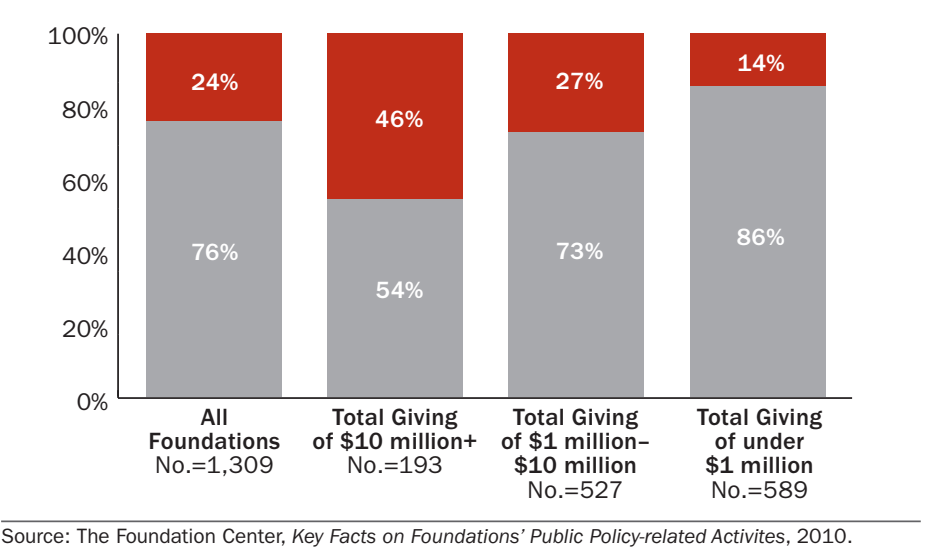

Source: The Foundation Center, Key Facts on Foundations' Public Policy-related Activites, 2010. 


\section{Has foundation support for public policy-related activities increased and what is the potential for growth going forward?}

- Over half of surveyed foundations that engage in public policy-related activities increased their levels of support over the last five years. In fact, close to two-fifths of these funders were not engaged in supporting public policyrelated efforts five years ago.

- While the majority of foundations expect their level of spending on public policy-related activities will remain the same over the next five years, just over one-quarter anticipate the level to increase.

- Among those foundations that do not currently engage in public policy-related activities, 6 percent of foundations responded that they would consider funding in this area in the future, while almost three-quarters (72 percent) replied that they would not.

\section{What are the primary focus areas and strategies of foundations' public policy-related activities?}

- The largest shares of surveyed foundations engage in public policy-related activities specifically focused on education and children and youth.

- Most foundations that are engaged in public policy-related activities are seeking to accelerate systems change and reform and improve the quality and reach of public information and education.

Foundations' Public Policy-related Activities by Fields of Interest, 2010

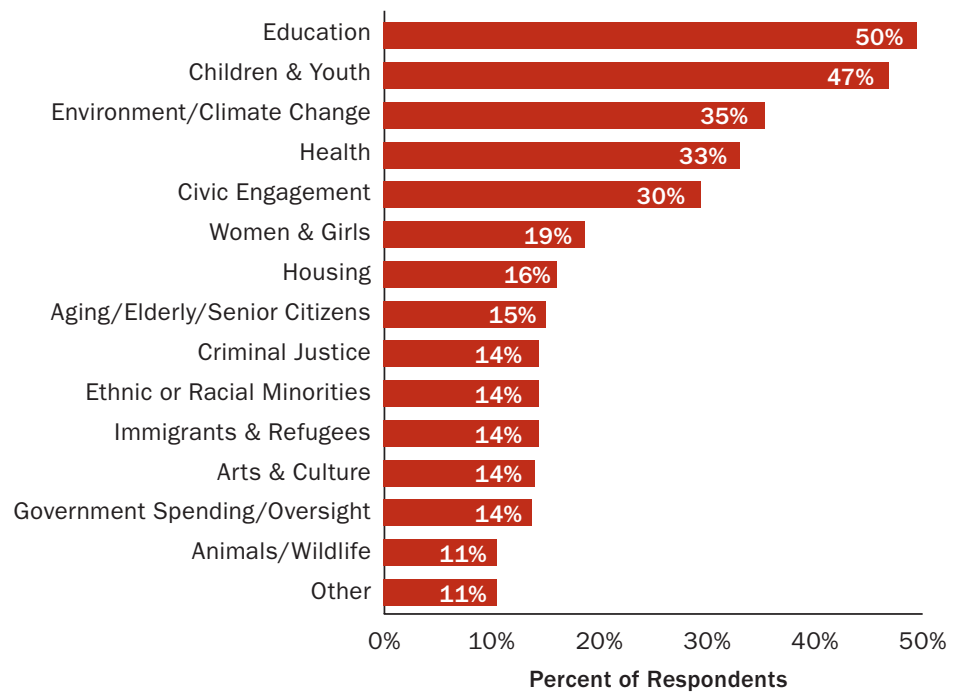

Source: The Foundation Center, Key Facts on Foundations' Public Policy-related Activites, 2010. Based on $\mathbf{3 0 5}$ foundations that engage in public policy-related activities.
Change in Level of Foundation Engagement in Public Policy-related Activities, 2005 to 2010

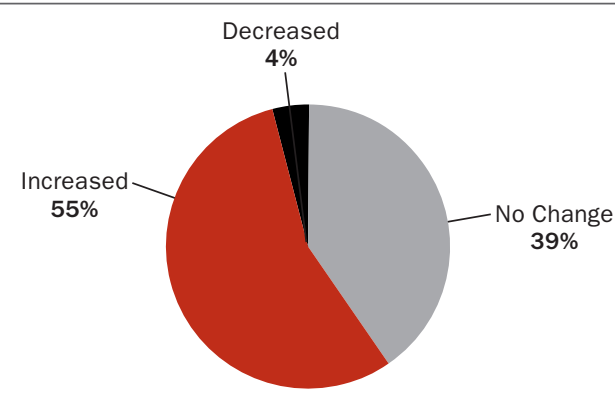

Percent of Respondents

Source: The Foundation Center, Key Facts on Foundations' Public Policy-related Activites, 2010. Based on 322 foundations that engage in public policy-related activities.

Anticipated Change in Level of Foundation Engagement in Public Policy-related Activities, 2010 to 2015

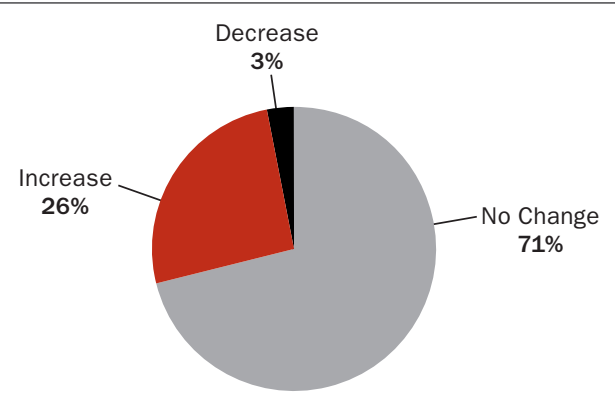

Percent of Respondents

Source: The Foundation Center, Key Facts on Foundations' Public Policy-related Activites, 2010. Based on 317 foundations that engage in public policy-related activities.

Foundations' Public Policy-related Activities by Strategies, 2010

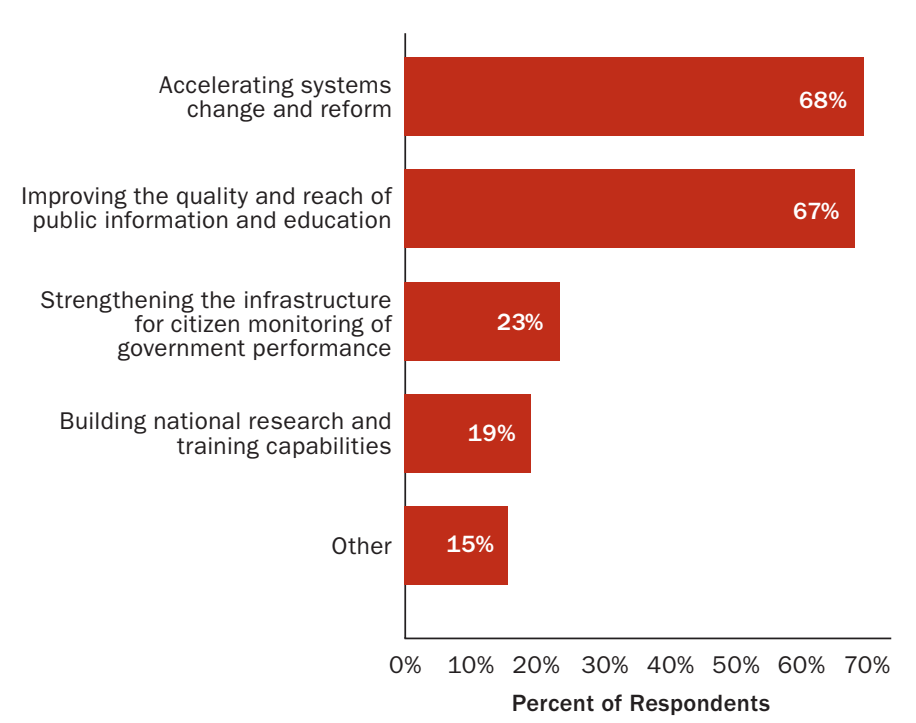

Source: The Foundation Center, Key Facts on Foundations' Public Policy-related Activites, 2010. Based on 307 foundations that engage in public policy-related activities. 


\section{In what ways do foundations engage in public policy-related activities?}

Most foundations that support public policy-related activities do so through grants to non-profit organizations, although one in five foundations conduct staff-led research and analysis.

\section{What is the overall share of foundations' charitable expenditures supporting public policy-related activities?}

About two-fifths of the foundations engaged in this work provide less than 5 percent of their overall charitable expenditures on public policy-related activities. At the other end of the spectrum, close to one out of five foundations provide more than 25 percent of their charitable expenditures for public policy-related activities.

\section{At what level of government do foundations engage in public policy-related activities?}

A majority of foundations' public policy-related activities focus on the state and local levels, with community foundations being most likely to focus on the local level (84 percent). Nonetheless, close to half of foundations supported public policy-related efforts at the national level.

Source for all data:

The Foundation Center

For more information about this advisory, contact communications@foundationcenter.org.

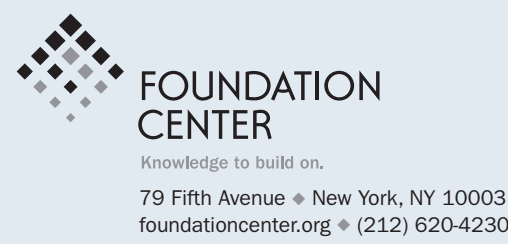

\section{ABOUT THE FOUNDATION CENTER}

Established in 1956 and today supported by close to 550 foundations, the Foundation Center is the leading source of information about philanthropy worldwide. Through data, analysis, and training, it connects people who want to change the world to the resources they need to succeed. The Center maintains the most comprehensive database on U.S. and, increasingly, global grantmakers and their grants - a robust, accessible knowledge bank for the sector. It also operates research, education, and training programs designed to advance knowledge of philanthropy at every level. Thousands of people visit the Center's web site each day and are served in its five regional library/learning centers and its network of 450 funding information centers located in public libraries, community foundations, and educational institutions nationwide and beyond. For more information, please visit foundationcenter.org or call (212) 620-4230.

"Key Facts on Foundations' Public Policy-related Activities" is available at foundationcenter.org.
Foundations' Public Policy-related Activities by Selected Types of Support, 2010

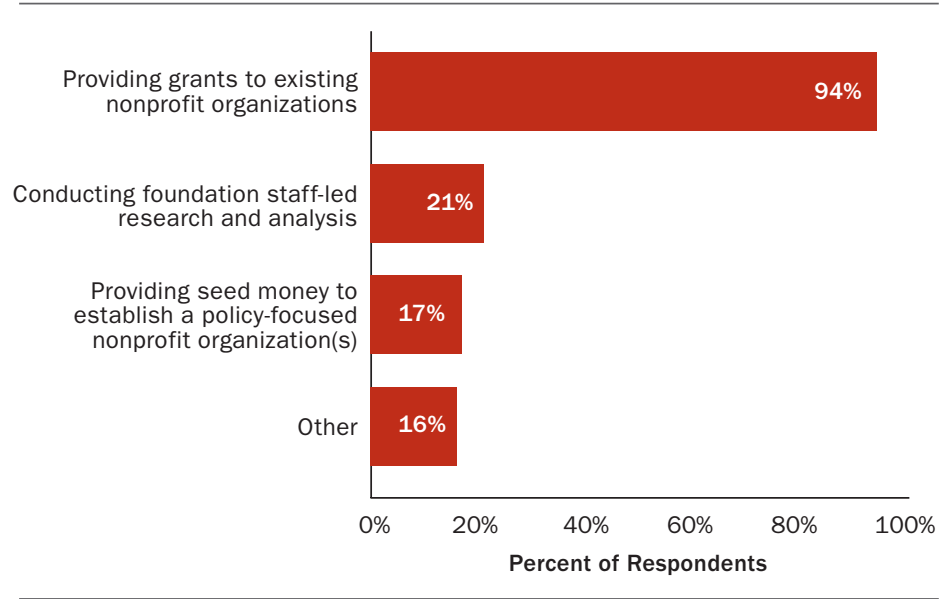

Source: The Foundation Center, Key Facts on Foundations' Public Policy-related Activites, 2010. Based on $\mathbf{3 1 4}$ foundations that engage in public policy-related activities.

\section{Share of Foundations' Overall Charitable Expenditures} Supporting Public Policy-related Activities, 2010

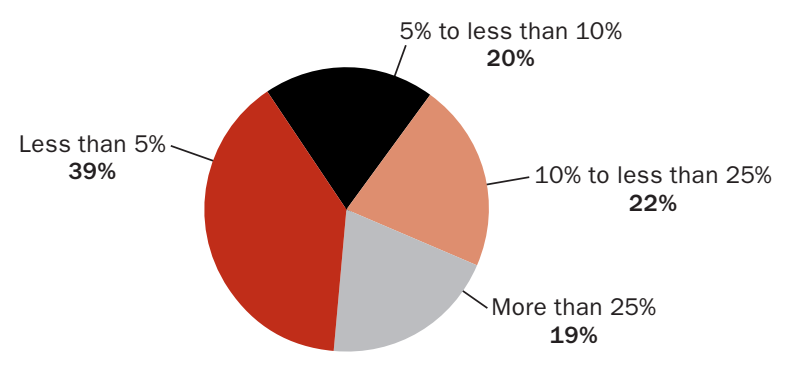

Percent of Respondents

Source: The Foundation Center, Key Facts on Foundations' Public Policy-related Activites, 2010. Based on $\mathbf{3 1 7}$ foundations that engage in public policy-related activities.

Foundations' Public Policy-related Activities by Geographic Focus, 2010

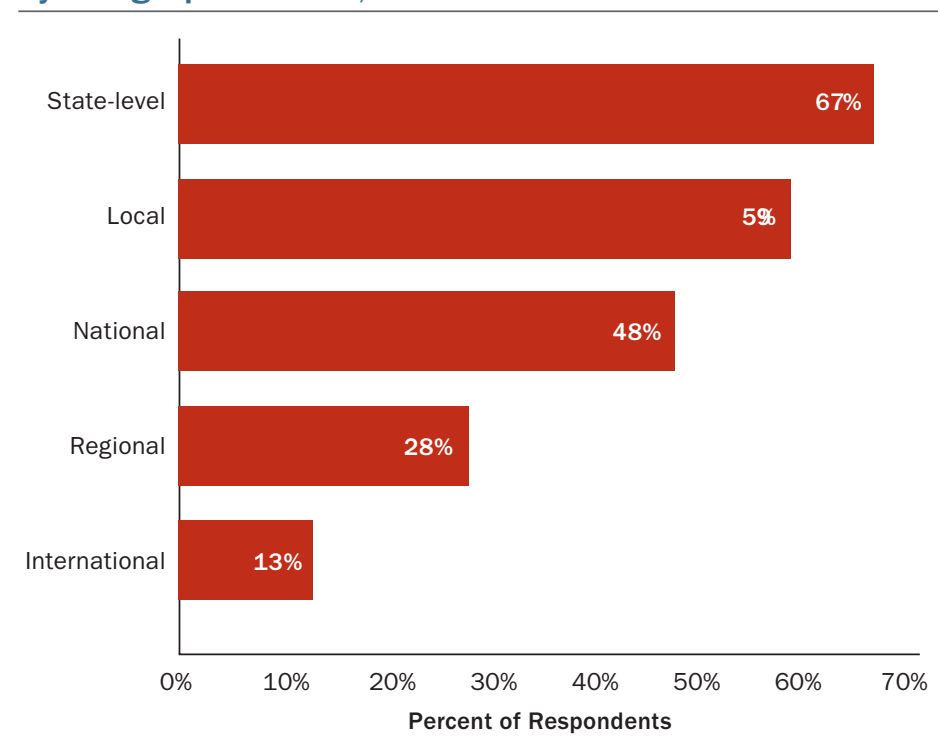

Source: The Foundation Center, Key Facts on Foundations' Public Policy-related Activites, 2010. Based on $\mathbf{3 1 7}$ foundations that engage in public policy-related activities. 